\title{
Surface modification using ionic liquid ion beams
}

\section{$\operatorname{AUTHOR}(\mathrm{S}):$}

Takaoka, Gikan H.; Hamaguchi, Takuya; Takeuchi, Mitsuaki; Ryuto, Hiromichi

\section{CITATION:}

Takaoka, Gikan H. ... [et al]. Surface modification using ionic liquid ion beams. Nuclear Instruments and Methods in Physics Research Section B: Beam Interactions with Materials and Atoms 2014, 341: 32-36

\section{ISSUE DATE:}

2014-12

URL:

http://hdl.handle.net/2433/192901

\section{RIGHT:}

C 2014 Elsevier B.V.; この論文は出版社版でありません。引用の際には 出版社版をご確認ご利用ください。; This is not the published version. Please cite only the published version. 


\title{
Surface modification by using ionic liquid ion beams
}

Gikan H. Takaoka, Takuya Hamaguchi, Mitsuaki Takeuchi, and Hiromichi Ryuto

Photonics and Electronics Science and Engineering Center, Kyoto University

Katsura, Nishikyo-ku, Kyoto 615-8510, Japan

\begin{abstract}
We developed the ionic liquid ion source, and the ionic liquid ion beams were produced by applying the high-electric field between the tip and the extractor. Ionic liquids used were 1-butyl-3-methylimidazolium hexafluorophosphate (BMIM-PF6). Time-of-flight measurement showed that small cluster ions as well as fragment ions were contained in positive and negative ion beams. The positive or negative cluster ions were deposited on $\mathrm{Si}(100)$ substrates. X-ray photoelectron spectroscopy measurement showed that the composition of deposited layers was similar to that of ionic liquid solvent. This suggested that a cation $\left(\mathrm{A}^{+}\right)$or an anion $(\mathrm{B})$ was attached to a ionic liquid cluster $(\mathrm{AB})_{\mathrm{n}}$ resulting in the formation of positive cluster ion $(\mathrm{AB})_{\mathrm{n}} \mathrm{A}^{+}$or negative cluster ion $(\mathrm{AB})_{n} \mathrm{~B}$, respectively. The surface of ionic liquid layers deposited on $\mathrm{Si}(100)$ substrates was flat at an atomic level for positive and negative cluster ion irradiation. Also, the contact angle of deposited layers was similar to that of ionic liquid solvent. Thus surface modification of $\mathrm{Si}(100)$ substrates was demonstrated with BMIM-PF 6 cluster ion beams.
\end{abstract}

Keywords: Cluster ions, Ionic liquid ions, Polyatomic ions, Ion beams, Surface modification 


\section{Introduction}

Ion beam technology is one example of ion-assisted material processing, and it has several advantages, one of which that various kinds of ion beams such as positive and negative, monomer and cluster ion beams, are available [1-5]. Also, alternative or simultaneous irradiation of positive and negative ion beams has attracted much attention as a useful approach in ion beam applications, and it opens up new fields in the material processing. Among these ion beams, cluster ion beams have several unique features, for example, simultaneously low energy and high current ion beams can be realized. Furthermore, the impact of cluster ions on solid surfaces is characterized by several unique irradiation effects, which include a high energy density, multiple collisions, and low energy irradiation effects [6-10]. For example, the multiple collision effect enhances the lateral motion of constituent atoms (or molecules) on the surface, which contributes to the formation of a flat surface. Taking account of these features, we have produced liquid cluster ion beams by exploiting a nozzle beam method [11-14]. With regard to the source materials, liquid materials are more appropriate than gaseous materials, as they tend to have more radicals in their polyatomic molecules than gaseous materials. These radicals play an important role in chemical erosion and sputtering of material surfaces [15-17].

On the other hand, ionic liquids (ILs) are room temperature molten salts with negligible vapor pressures. They contain equal amount of cations and anions, which are polyatomic molecules. They exhibit many features which are advantageous for a number of applications such as synthetic chemistry, catalysis, photochemistry and electrochemistry [18-20]. In addition, the surface modification of semiconductor substrates by ionic liquids have recently attracted much interest, and they are used as electrolyte dielectrics to realize very high field-induced carrier densities in the conducting channel of a field-effect transistor [21,22]. In this device application, it is of much importance to prepare ILs thin layers with good adhesion and atomically flat 
interface. The ILs ion beams have been created by an electrospray ion source. These beams were characterized by in situ time-of-flight (TOF) mass spectrometry [5].

The ILs thin layers with good adhesion could be formed on a substrate by cluster ion beam deposition. However, in order to produce ILs cluster ion beams, the nozzle beam method using an adiabatic expansion phenomenon cannot be applied because the vapor pressure of ILs is extremely low. As a new approach to the liquid cluster ion generation, we have developed an ILs ion source using a high electric field method [23,24], and applied it to material processing. In this article, we modify the IL ion source for generation of stable ion beams, and the mass analysis of ionic liquid ion beams is performed by using 1-butyl-3-methylimidazolium hexafluorophosphate $\left(\mathrm{BMIM}-\mathrm{PF}_{6}\right)$. The production of positive and negative cluster ions is investigated. Furthermore, irradiation of ionic liquid cluster ions on Si substrates is performed at room temperature, and surface modification of the substrates is investigated.

\section{Experimental}

ILs ion beam system is similar of that previously described [23]. A high-electric field method was employed for the ion-emission from a sharp tip. ILs used was 1-butyl-3methylimidazolium hexafluorophosphate $\left(\mathrm{BMIM}-\mathrm{PF}_{6}\right)$. Because the drop of ILs was initially fed directly on the tip of the needle, the wettability of ILs was an important factor. As shown in Table 1, the contact angle of the ionic liquid (BMIM-PF 6 ) put on a carbon plate is $32.5 \mathrm{deg}$, and carbon exhibits better wettability for BMIM-PF 6 than $\mathrm{W}$ and stainless steel (SUS). Also, as carbon is an excellent material in mechanical processing, the needle was made of carbon. The diameter of the carbon needle was 0.3 mm. As a tip designed, for example, a needle with a radius of $80 \mu \mathrm{m}$ was employed. The needle was supported on the porous electrode covered with carbon felt. The porous electrode instead of the SUS pipe, which was used in the previous ion source, was made of SUS, and it was connected to ILs reservoir. The thickness of the felt was 
approximately $100 \mu \mathrm{m}$, and the porosity of felt-covered electrode was estimated to be approximately $50 \%$. Also, the needle was biased either positively or negatively with respect to a nearby aperture electrode which served as the extractor. The orifice prepared on the aperture electrode was $2 \mathrm{~mm}$ in diameter. An extractor was placed at approximately $3 \mathrm{~mm}$ away from the tip. The ionic liquid ions were emitted from the tip by applying the voltage between the tip and the extractor. The potential difference generates an electric field that is particularly intense over the emitter surface. As opposed to most ion sources either positive or negative ion beams can be extracted from ILs ion source depending only on the direction of the applied electric field, i.e. selecting the appropriate polarity of the voltage source. The extraction voltage was adjusted to be between $0 \mathrm{kV}$ and $10 \mathrm{kV}$. The extracted ion beams were accelerated toward a substrate. The acceleration voltage was adjusted to be between $0 \mathrm{kV}$ and $10 \mathrm{kV}$. The ion beams deposition on the substrate was performed at lower acceleration voltages. The substrate used was $\mathrm{Si}(100)$ substrate. The background pressure around the substrate was $1.0 \times 10^{-6}$ Torr, which was attained using a diffusion pump.

With regard to the mass analysis, the mass over charge ratio $\mathrm{m} / \mathrm{q}$ of the various particles produced was determined by time of flight (TOF) mass spectrometry [15]. In the TOF measurement, the linear mode operation and one stage acceleration method were used. The ion beam was interrupted by applying a pulse voltage at time $t=0$ and the arrival time distribution of ion current received at a Micro Channel Plate (MCP) detector was measured. The flight distance was $1.7 \mathrm{~m}$, and the time of flight measured was in a range of $10 \mathrm{\mu s}$. When energetic ions reached the top plate of the MCP, secondary electrons were emitted and were amplified exponentially in the channel plate. On the assumption that all the particles have a kinetic energy per unit charge equal to the voltage difference $\mathrm{V}$, the current curve yields the distribution of $\mathrm{m} / \mathrm{q}$. It should be noted that it is important to measure the energy distribution for more accurate mass-analysis. 


\section{Results and discussion}

With regard to the ion beam characteristics, both positive and negative ions started to be emitted at an extraction voltage of approximately $4 \mathrm{kV}$. The surface tension of BMIM- $\mathrm{PF}_{6}$ is $0.049 \mathrm{~N} / \mathrm{m}$. Also, the tip radius was $80 \mu \mathrm{m}$, and the distance between the tip and the extractor was $3 \mathrm{~mm}$. Therefore, the threshold voltage was estimated to be a few kilovolts, and it was close to the experimental result, i.e. $4 \mathrm{kV}$. The ions extracted were moved toward a Faraday cup, on which they were collected as an ion current. The ion current for BMIM-PF 6 increased with increasing extraction voltage, and the ion current at an extraction voltage of $6 \mathrm{kV}$ was approximately $70 \mathrm{nA}$ for positive ions and approximately $80 \mathrm{nA}$ for negative ions, respectively.

In order to investigate the stability of ILs ion beams, the extractor was placed more closely at approximately $0.5 \mathrm{~mm}$ away from the tip. Figure 1 shows the time dependence of ILs ion currents for (a) positive and (b) negative ions as a parameter of the extraction voltage $\left(V_{\text {ext }}\right)$. The pulse currents are observed at the extraction voltages such as $2.65 \mathrm{kV}$ and $2.7 \mathrm{kV}$. The pulse period decreases with increasing the extraction voltage, and the continuous currents were achieved at an extraction voltage of $2.8 \mathrm{kV}$. Moreover, the continuous currents were stable for a long time, e.g., one hour. If the number of cations or anions extracted is much larger than that of anions or cations remained, the extracted current becomes unstable, for example, in an electrospray method. On the other hand, in the ILs ion source developed, the porous felt-electrode was placed around the tip, and the flow rate of ILs toward the tip could be adjusted by the porosity. In addition, the high electric field induced by applying the extraction voltage to the tip could control the flow rate. As a result, the stable current was obtained by adjusting the extraction voltage as well as the porosity of the flowing space.

Figure 2 shows the mass spectra for (a) positive and (b) negative ionic liquid ion beams. The extraction voltage $\left(V_{\text {ext }}\right)$ was $4 \mathrm{kV}$. As shown in the figure, several peaks 
appear in the mass spectra for positive and negative ions, although the mass resolution is not sufficient at higher masses. The molecular weight of cation $\left(\mathrm{C}_{8} \mathrm{H}_{15} \mathrm{~N}_{2}\right)$ and anion $\left(\mathrm{PF}_{6}\right)$ is 139.22 and 144.96 , respectively. Both cations and anions are produced as positive and negative fragment ions. Furthermore, by assuming that singly charged ions are extracted, positive and negative cluster ions with a size of a few molecules to a few tens molecules are produced. Cluster sizes, for example, 3 molecules as well as 5, 7, 11, and 15 molecules are estimated from several peaks of the spectra. It was reported that multiply charged clusters could be produced by using salt with higher ionic bonding $[25,26]$. However, the TOF measurement cannot distinguish the singly charged cluster with a mass $(\mathrm{m})$ from the doubly charged cluster with a double-mass $(2 \mathrm{~m})$. Therefore, we assumed that singly charged ions were extracted. In addition, ILs clusters have the ionic bonding ability, and the same number of cations and anions form a neutral ILs cluster. For example, a cation $\left(\mathrm{A}^{+}\right)$or an anion $\left(\mathrm{B}^{-}\right)$is attached to the neutral cluster $(\mathrm{AB})_{\mathrm{n}}$, which results in the formation of a positive cluster ion $(\mathrm{AB})_{n} \mathrm{~A}^{+}$or negative cluster ion $(A B)_{n} B^{-}$with the cluster size of $n$.

The composition of ILs layers deposited on $\mathrm{Si}(100)$ substrates was measured by an X-ray photoelectron spectroscopy (XPS). Figure 3 shows (a) $\mathrm{F}_{1 \mathrm{~s}}$, (b) $\mathrm{N}_{1 \mathrm{~s}}$, and (c) $\mathrm{P}_{2 \mathrm{p}}$ peaks for BMIM-PF6 layers deposited by positive and negative ion beams. The acceleration voltage was $6 \mathrm{kV}$, and the ion dose was $1.0 \times 10^{15} \mathrm{ions} / \mathrm{cm}^{2}$. Compared with the XPS peaks for deposited layers, the peaks for BMIM-PF 6 solvent are stronger by approximately 10 times, because much solvent are attached to the Si surface. Moreover, the deposited layer was very thin. The layer thickness was estimated to be less than 5 nm because a Si peak was observed very weakly. Furthermore, XPS peaks observed correspond to the constituent elements in a BMIM- $\mathrm{PF}_{6}$ molecule. For example, $\mathrm{N}$ atoms are included in a cation, and $\mathrm{F}$ and $\mathrm{P}$ atoms are included in an anion. The composition ratio of these atoms, which can be estimated with respect to carbon atoms, is similar to that of ionic liquid $\left(\mathrm{BMIM}-\mathrm{PF}_{6}\right)$ solvent. According to the TOF measurement, ionic 
liquid cluster ions as well as fragment ions were produced. Therefore, the observation of XPS peaks for constituent elements indicates that either a cation or an anion is attached to the neutral BMIM- $\mathrm{PF}_{6}$ cluster resulting in the formation of positive or negative cluster ions, respectively.

In addition, the XPS peak intensities are similar between positive and negative ion irradiation. Also, the chemical shift for $\mathrm{N}_{\text {is }}$ and $\mathrm{P}_{2 \mathrm{p}}$ peaks is observed, although $\mathrm{F}_{1 \mathrm{~s}}$ peak position is not shifted. This indicates that the dissociation of a cation and an anion occurs after impact on the substrate surface, and the fragment atoms such as $\mathrm{N}$ and $\mathrm{P}$ atoms react with another atom such as $\mathrm{C}$ and $\mathrm{O}$ atom. With regard to the fragment atoms, small cluster ions as well as the cation and anion could also be dissociated. If the acceleration voltage is $6 \mathrm{kV}$ for small cluster ions, for example, with a size of 4 molecules, the incident energy is approximately one hundred electron volts per constituent atom. This is high incident energy, and the dissociation of a BMIM-PF 6 molecule contained in the positive and negative clusters might be occurred. Ion/surface collision phenomena in the hyperthermal collision energy regime $(1-100 \mathrm{eV})$ were reviewed in the references $[15,16]$. It was reported that inelastic collisions including soft landing could lead to excitation of the polyatomic projectile ions, resulting in the fragmentation described in terms of surface-induced dissociation (SID). Thus, fragment atoms produced are mixed in the ILs layers formed. It should be noted, however, that the large cluster ions contribute to the ILs deposition by keeping a molecular state of BMIM-PF 6 without dissociation. Also, the number of BMIM-PF 6 molecules transferred by large cluster ion beams is large because it is multiplied by the cluster size.

The surface morphology of deposited layers on Si (100) substrates was investigated by an atomic force microscope (AFM). Figure 4 shows AFM images of Si substrates unirradiated and irradiated by positive and negative cluster ions. The acceleration voltage was $8 \mathrm{kV}$, and the ion dose was $1.0 \times 10^{15}$ ions $/ \mathrm{cm}^{2}$. The scanning area was $1000 \mathrm{~nm} \times 1000 \mathrm{~nm}$. Although Si substrates irradiated by the cluster ion beams were 
rinsed by acetone, the deposited layers were found to remain by the XPS measurement. As shown in the figure, the Si surface becomes rough after deposition, and the surface roughness $(\mathrm{Ra})$ is $0.64 \mathrm{~nm}$ and $0.70 \mathrm{~nm}$ for positive and negative cluster ion irradiation, respectively. It is larger than that of the unirradiated surface, i.e., $0.16 \mathrm{~nm}$. Also, the surface morphology of deposited layers by positive and negative cluster ion beams represents the specific waves. The change of morphology is performed by deposition of ILs soft materials.

Figure 5 shows the dependence of the surface roughness on the acceleration voltage. The ion dose was $1.0 \times 10^{15}$ ions $/ \mathrm{cm}^{2}$. A shown in Figure 5, the surface roughness increased with increasing the acceleration voltage, and it was approximately $0.70 \mathrm{~nm}$ at an acceleration voltage of $8 \mathrm{kV}$. Because ILs is soft materials, the irradiation of highenergetic cluster ions as well as fragment ions on ILs under-layers causes the increase of surface roughness.

The wettability of Si (100) surfaces irradiated by ILs cluster ion beams were investigated by measuring the contact angles for water droplet, which was put on the Si surfaces just after taking out of the vacuum chamber. Before the cluster ion irradiation, the $\operatorname{Si}(100)$ surfaces were cleaned with hydrofluoric acid and pure water. Figure 6 shows the dependence of the contact angle on the ion dose for the positive and negative cluster ion irradiation. The acceleration voltage was $8 \mathrm{kV}$. The contact angle for the unirradiated Si-surface was 74.4 degree. As shown in the figure, the contact angle for the negative cluster ion irradiation decreases, and it is approximately 50 degree. This is the same as the contact angle of ILs layers formed on the Si surface by a dipping method. On the other hand, for the positive cluster ion irradiation, the contact angle is less than 50 degree at an ion dose of $5.0 \times 10^{14} \mathrm{ions} / \mathrm{cm}^{2}$, and it increases to be approximately 50 degree with increasing the ion dose. This indicates that the ILs layers are formed on the Si surface even at a lower ion dose. It is noted that the surface modification of Si substrates is performed by deposition of the ILs cluster ions. 
Figure 7 shows the dependence of the contact angle on the acceleration voltage for the positive and negative cluster ion irradiation. The ion dose was $1.0 \times 10^{15}$ ions $/ \mathrm{cm}^{2}$. As shown in the figure, the contact angle is approximately 50 degree for most the irradiated surfaces, although it is smaller for negative cluster ion irradiation at an acceleration voltage of $6 \mathrm{kV}$. According to the AFM observation, the surface roughness of the deposited layers increased with increasing the acceleration voltage. However, the contact angle is almost the same at different acceleration voltages, and it is independent of the change of surface roughness. Since the ILs is soft matter without mixing water, the interaction of water droplets with deposited ILs-layers is weak. As a result, the contact angle for deposited layers is constant. Furthermore, for fragment ions as well as small cluster ions, the incident energy is larger than a few hundreds electron volts per atom. The ILs layers including fragment atoms might be deposited on the substrate surface, which results in the surface modification of Si substrates.

The adhesion of ILs deposited layers on Si substrates was stronger than the ILs solvent, because they were not removed by acetone rinse. It is considered that good adhesion of the ILs layers might be performed by chemical bonding of a cation or an anion with the Si surface atom. In order to show that ILs layers deposited were transparent and electric conductive, we measured the transmittance and the scanning electron microscope (SEM) image for ILs layers deposited on glass substrates [27]. The deposition condition was the same as that for $\mathrm{Si}(100)$ substrates. According to the measurement, the transmittance of the ILs layers deposited by the positive and negative cluster ion beams was the same as that of the glass substrate. This suggested that the deposited layers were transparent, although the layer thickness was very thin. In addition, the SEM images of glass substrates were observed clearly without chargeup of electron beams. This was ascribed to the deposition of ionic liquids exhibiting electric conductivity. 


\section{Conclusions}

We developed the ionic liquids (ILs) ion source using the high electric field method, and produced both positive and negative ILs ion beams. TOF measurement showed that cluster ions of ILs (BMIM-PF $)$ as well as fragment ions such as cation (BMIM) and anion $\left(\mathrm{PF}_{6}\right)$ were produced. The cluster size was distributed between a few molecules and a few tens molecules. With regard to the cluster ions, a cation $\left(\mathrm{A}^{+}\right)$or an anion (B) was attached to a ionic liquid cluster $(\mathrm{AB})_{\mathrm{n}}$ resulting in the formation of positive cluster ion $(A B)_{n} A^{+}$or negative cluster ion $(A B)_{n} B$, respectively. Furthermore, the positive and negative cluster ion beams including the fragment ions were deposited on $\mathrm{Si}(100)$ substrates, and the deposited layers with the flat surface at an atomic level was formed. XPS measurement showed that the composition of deposited layers was similar to that of ILs solvent. Also, the contact angle of $\mathrm{Si}(100)$ surfaces irradiated at different acceleration voltages and ion doses was similar to that of ILs solvent. 


\section{References}

[1] H. Haberland: "Clusters of Atoms and Molecules" (Springer-Verlag, Berlin, 1994).

[2] P. Lozano and M. Martinez-Sanchez, J. Coll. Interface Sci., 282 (2005) 415.

[3] D.J. Stokes, L. Roussel, O. Wilhelmi, L.A. Giannuzzi and D. HW Hubert, Mater. Res. Soc. Proc. 1020 (2007) 15.

[4] J. Ishikawa, Rev. Sci. Instrum. 79 (2008) 02 C506.

[5] S. Rauschenbach, R. Vogelgesang, N. Malinowski, J.W. Gerlach, M. Benyoucef, G. Costantini, Z. Deng, N. Thontasen and K. Kern, ACS Nano 3 (2009) 2901.

[6] H. Hsieh and R.S. Averback, Phys. Rev. B42 (1990) 5365.

[7] R.S. Averback, M. Ghaly and H. Zhu, Radiat. Eff. Defects Solids 130-131 (1994) 211.

[8] Z. Insepov, I. Yamada and M. Sosnowski, Mater. Chem. Phys. 54 (1998) 234.

[9] M. Moseler, O. Rattunde, J. Nordiek and H. Haberland, Nucl. Instrum. Methods B164-165 (2000) 522.

[10] H. Yasumatsu and T. Kondow, Rep. Prog. Phys. 66 (2003) 1783.

[11] G.H.Takaoka, M. Kawashita and T. Okada, Mater. Res. Soc. Proc. 1020 (2007) 159.

[12] G.H. Takaoka, M. Kawashita and T. Okada, Rev. Sci. Instrum. 79 (2008) 02C503.

[13] H. Ryuto, K. Tada and G.H. Takaoka, Vacuum 84 (2010) 501.

[14] G.H. Takaoka, H. Ryuto and M Takeuchi, J. Mater. Res., 27 (2012) 806.

[15] V. Grill, J. Shen, C. Evans and R.G. Cooks, Rev. Sci. Instrum. 72 (2001) 3149.

[16] B. Gologan, J.R. Green, J. Alvarez, J. Laskin and R.G. Cooks, Phys. Chem. Chem. Phys. 7 (2005) 1490.

[17] W. Jacob and J. Roth, in R. Behrisch and W. Eckstein (Eds.): "Sputtering by Particle Bombardment" Top. Appl. Phys. 110 (Springer, Berlin, Heidelberg, New York, 2007) p.329.

[18] K. Binnemans, Chem. Rev. 107 (2007) 2592.

[19] H. Zhao, J.E. Holladay, H. Brown and Z.C. Zhang, Science 316 (2007) 1597.

[20] N. V. Plechkova and K.R. Seddon, Chem. Soc. Rev. 37 (2008) 123. 
[21] J.H. Cho, J. Lee, Y. Xia, B. Kim, Y. He, M.J. Renn, T.P. Lodge and C.D. Frisbie, Nature Mater. 7 (2008) 900.

[22] A.S. Dhoot, C. Israel, X. Moya, N.D. Mathur and R.H. Friend, Phys. Rev. Lett. 102 (2009) 136402.

[23] G.H. Takaoka, M. Takeuchi and H. Ryuto, Rev. Sci. Instrum., 81 (2010) $02 B 302$.

[24] M. Takeuchi, H. Ryuto, and G.H. Takaoka, in 18th Int. Conf. on Ion Implant. Technol., edited by J Matsuo, T. Aoki and T. Seki (AIP Conf. Proc.,2010) p.456.

[25] D.X. Zhang and R.G. Cooks, Int. J. Mass Spectrom. 196 (2000) 667.

[26] M. Gamero-Castano and J.F. de la Mora, Analy. Chim. Acta 406 (2000) 67.

[27] G.H. Takaoka, M. Takeuchi, H. Ryuto and R. Ueda, Nucl. Instrum. Methods B307, (2013) 257. 


\section{Table caption}

Table 1: Contact angles of ionic liquids (BMIM-PF $)$ on carbon (C), tungsten (W), and stainless (SUS).

\section{Figure captions}

Figure 1: Time dependence of ILs ion currents for (a) positive and (b) negative ions as a parameter of the extraction voltage $\left(V_{\text {ext }}\right)$.

Figure 2: Mass spectra for (a) positive and (b) negative ionic liquid ion beams.

Figure 3: (a) $\mathrm{F}_{1 \mathrm{~s}}$, (b) $\mathrm{N}_{1 \mathrm{~s}}$, and (c) $\mathrm{P}_{2 \mathrm{p}}$ peaks for BMIM-PF 6 layers deposited by positive and negative ion beams. The acceleration voltage was $6 \mathrm{kV}$, and the ion dose was $1.0 \times 10^{15} \mathrm{ions} / \mathrm{cm}^{2}$.

Figure 4: AFM images of Si substrates (a) unirradiated and irradiated by (b) positive and (c) negative cluster ions. The acceleration voltage was $8 \mathrm{kV}$, and the ion dose was $1.0 \times 10^{15}$ ions $/ \mathrm{cm}^{2}$.

Figure 5: Dependence of the surface roughness on the acceleration voltage. The ion dose was $1.0 \times 10^{15} \mathrm{ions} / \mathrm{cm}^{2}$.

Figure 6: Dependence of the contact angle on the ion dose for the positive and negative cluster ion irradiation. The acceleration voltage was $8 \mathrm{kV}$. 
Figure 7: Dependence of the contact angle on the acceleration voltage for the positive and negative cluster ion irradiation. The ion dose was $1.0 \times 10^{15} \mathrm{ions} / \mathrm{cm}^{2}$. 


\begin{tabular}{|c|c|c|}
\hline $\mathrm{C}$ & W & SUS \\
\hline $32.5 \mathrm{deg}$ & $65.8 \mathrm{deg}$ & $50.6 \mathrm{deg}$ \\
\hline
\end{tabular}

Table 1: Takaoka et al. 



Figure 1: Takaoka et al. 

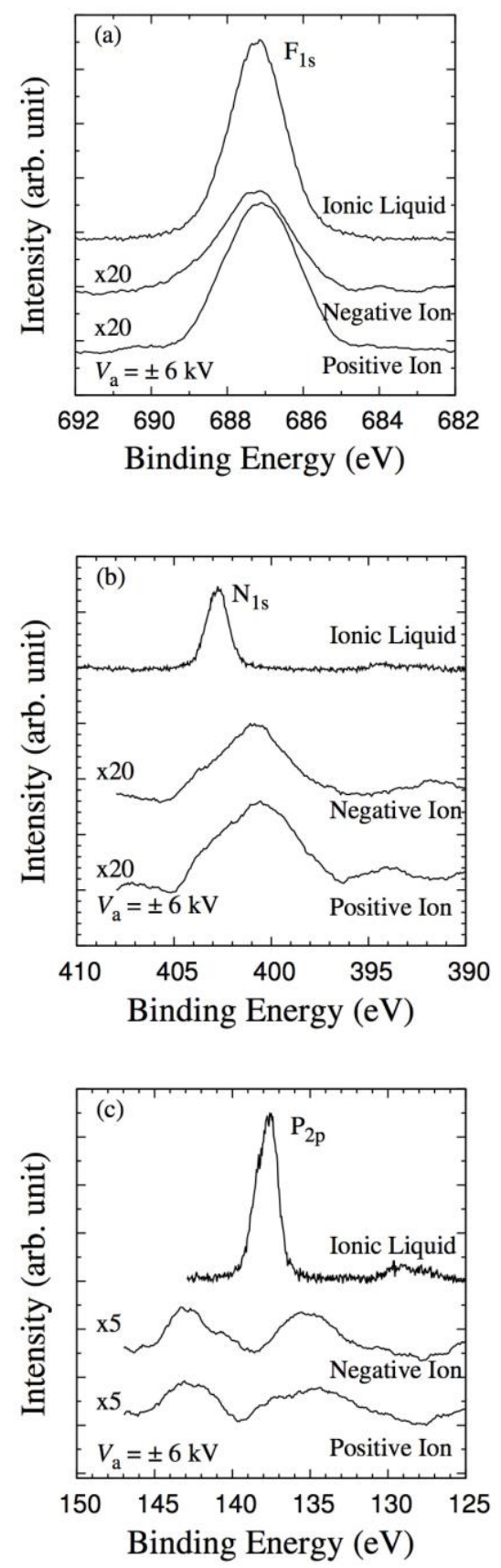

Figure 2: Takaoka et al. 

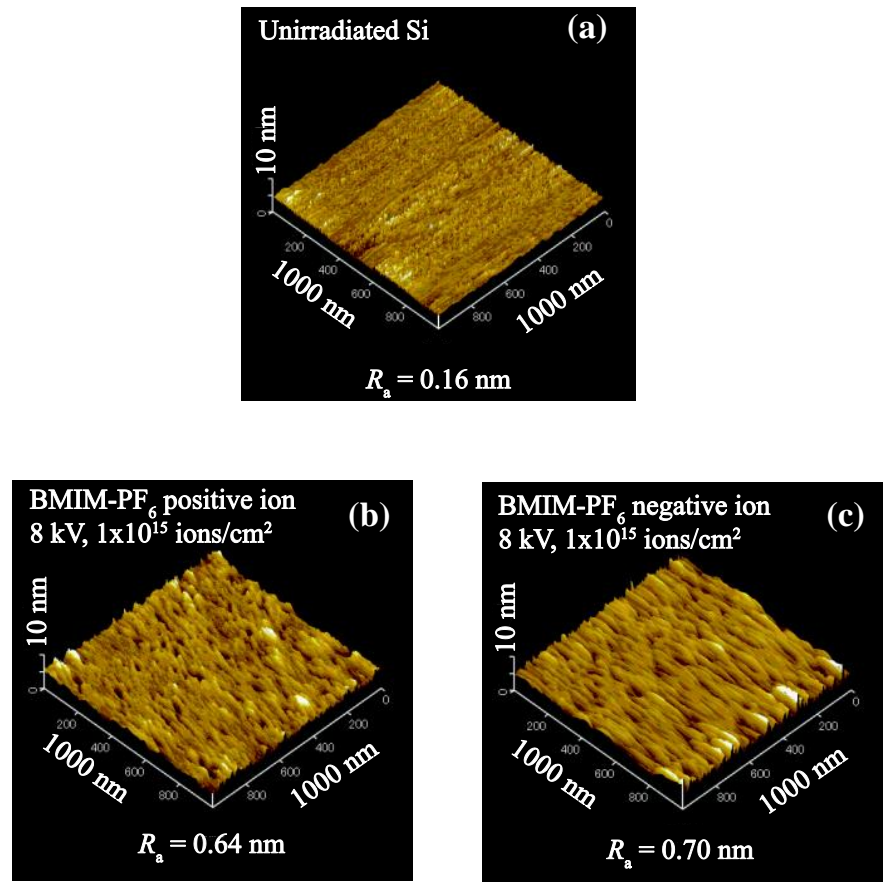

Figure 3: Takaoka et al. 


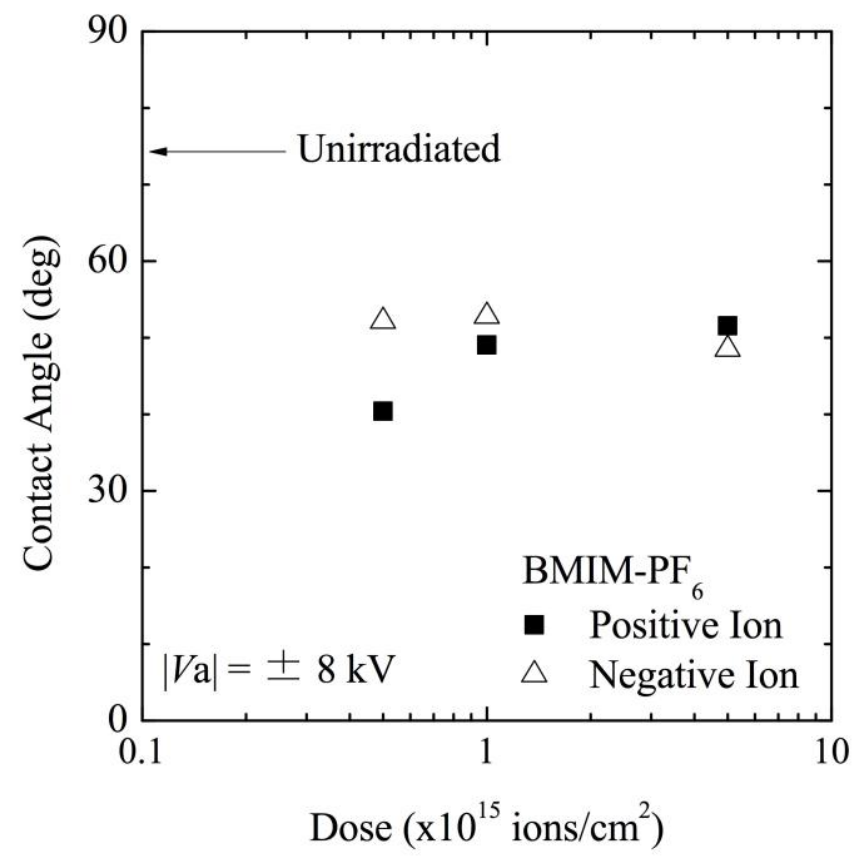

Figure 4: Takaoka et al. 


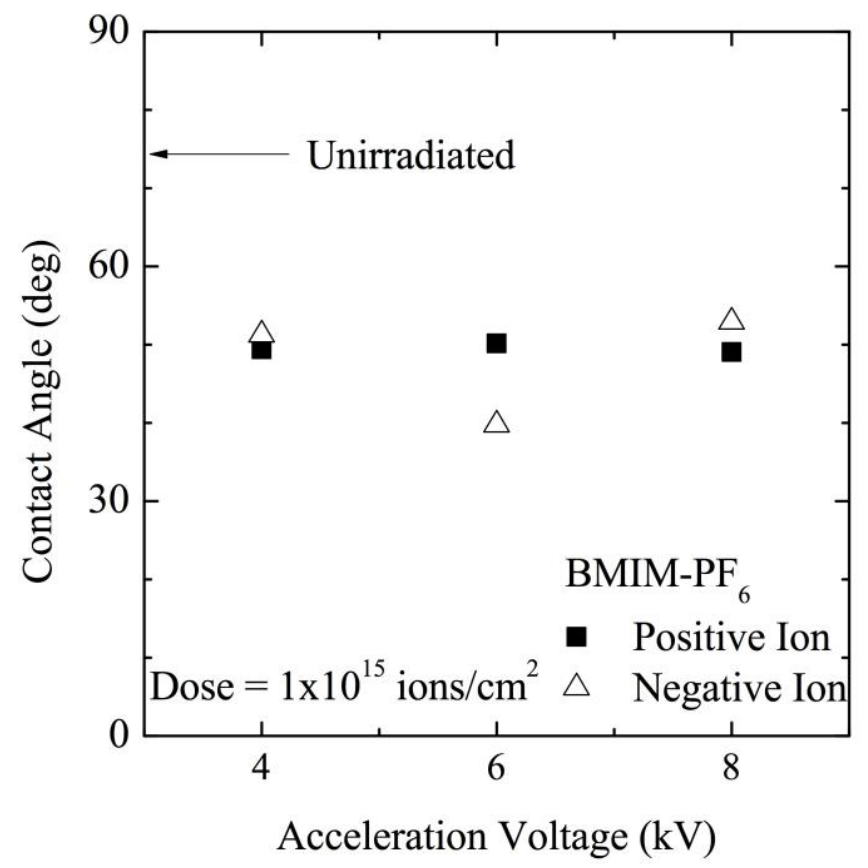

Figure 5: Takaoka et al. 